\title{
Evolutionary Studies in Business: A Presentation of a New Journal
}

\begin{abstract}
The Journal of Evolutionary Studies in Business is a new open access journal led by an international interdisciplinary team of scholars located in eight institutions from three continents who wants to attract contributions that help shed light on the new questions, challenges, methodologies and realities, faced by businesses in an evolutionary perspective. The journal calls particularly for review essays that deal with new research topics about business, and provide useful overviews of the key ideas, scholars, and debates about important research topics concerning business and its environment. The strategic areas of interest for submissions from authors are: Management Challenges, Entrepreneurship, Science and Business, Creative Industries, International Business, Business History, and Latin American Businesses. JESB will also publish articles about relevant online resources that contain information of interest to academic scholars and business practitioners.
\end{abstract}

Keywords: Evolutionary Perspectives; Management Challenges; Entrepreneurship; Science and Business; Creative Industries; International Business; Business History; Latin American Businesses; Online Resources for Business.

Corresponding author. E-mail: palomafernandez@ub.edu

Received 15 November 2015 - Accepted 22 December 2015

This is an Open Access article distributed under the terms of the Creative Commons Attribution-Non-Commercial-No Derivatives License (http://creativecommons.org/licenses/by-nc-nd/4.0/), which permits non-comercial re-use and distribution, provided the original work is properly cited, and is not altered or transformed in any way. 


\section{Key issues behind this new open access journal}

The academic publishing industry is moving in the direction of a dual market. On the one hand, we have an oligopolistic concentration of big publishers that are increasingly accumulating elite high impact factor authors and articles. On the other hand, we are witnessing the multiplication of online open access journals where quality factors beyond citations are difficult to homogenize as they differ in the diversity of their quality criteria. Moreover, many of these journals are produced for free and others are extremely expensive, some are sponsored by institutions while others by unknown individuals.

The Journal of Evolutionary Studies in Business is a free open access journal led by an editorial team of experts located in eight institutions from three different continents. The Editors-in-Chief and Associate Editors are well-known researchers with expertise in a diversity of fields related to business, and a shared willingness to prioritize the publication of high quality reviews and surveys that take into account dynamism and context in the analysis of business organizations, as well as the relationship between businesses and the environment. There are many quality academic journals that publish original research and compete at a global level in order to attract authors and citations and increase their impact factor indexes year by year in order to, in turn, increase their number of authors and citations and the level of influence they have among the globalized academic community. In the midst of this process, the question many researchers are increasingly asking themselves is: what for and why? Professional and promotional reasons stand out for many as a powerful key to understanding the current pressures of 'publish or perish' academic life. One must not overlook the contextual environment of institutions, from the regional to the continental level, that provide 
subsidies for academic jobs, promotions, and projects based on impact factor indexes as the almost standardized homogeneous global criteria of excellence in Science. Some researchers think this is not easily sustainable in the long run due to the current instability in the creation of academic jobs around the world and the bottleneck in access to high impact factor journals, as well as the relatively high prices many impose on authors in order to publish quickly in an open access way that facilitates increased citations and promotion.

Our most important goal, in this context, is to have an open access journal that imposes internationally accepted high-quality criteria with the chief aim of satisfying the increased demand for online high quality contributions about business from an evolutionary perspective. Our long-term editorial strategy, from this volume onwards, will be in this regard to publish online peer-reviewed contributions, use standard international publishing criteria, and apply as soon as possible for an impact factor index that will mean additional benefits for authors and readers.

A second contribution this journal will make to the current needs of academic researchers is to invest our efforts in giving new explicit added value to high quality reviews, overviews and surveys of existing research. This is not completely new since top academic journals in diverse areas studying business like the Journal of Management and Business History or the International Journal of Management Reviews are starting to pay attention through calls for reviews for special issues in their journals, thus acknowledging the need to have experts select and analyze relevant knowledge and research in areas of interest to the academic community. Excellence and social impact in all scientific disciplines have often (in the last three decades) been measured and evaluated in peer-reviewed high impact factor journals by considering the quantity and quality of original research based on primary sources or new methodological 
contributions. However, the Internet has multiplied the number of journals that publish original research at such a speed that it is extremely and increasingly difficult to keep track of and be up-to-date on key contributions, key questions, and new fields of research. Besides, since Greek and Roman times, the foundations of Science have been based above all on the Socratic search for quality in the kinds of questions and hypotheses scientists discuss among themselves and with others, not just in the accumulation of new original evidence. A good journal that focuses on excellent reviews can contribute, using Schumpeterian terminology, to creative destruction in the combination of ideas and resources, helping to build new thinking and thus making room for new understandings of past events, innovative research, and new questions.

In the age of mass flows of information online and the effects on increasing speed in the global network of brains, Science requires, more than in the pre-internet past, not just accumulated new original pieces of research or new methodological contributions to add to the ones that already exist. It requires tools for synthesis that help prioritize key issues and key questions. A journal specialized in overviews of key research topics around business from a dynamic perspective can contribute to this major challenge faced by Science and Business today. It is for this reason that the editors of the Journal of Evolutionary Studies in Business firmly believe that today there is a very attractive market niche that is wide open for journals that use new technologies to publish excellent surveys on research that may appeal to diverse readers of different origins and interests. Surveys are, therefore, the priority target of the Journal of Evolutionary Studies in Business since to our understanding they are a specialized type of text that prioritizes ideas and questions that can reach a global academic audience. Our surveys will involve the work of expert authors that develop, in a clear and synthesized way, 
thought-provoking overviews of relevant topics, highlighting the key questions, the key debates, and the key authors, suggesting further readings and new research for a scholarly audience, and guiding policymakers and practitioners involved in the business environment. Thirdly, the Journal of Evolutionary Studies in Business contributes to the abundant supply of journals on business and management with its own original voice. It does so not just by using an open access online platform and providing high-quality overviews and theoretical insights about evolution in business. Its originality lies, additionally, in the fact that it focuses on evolution, not just change. These are not exactly synonyms. That business is in constant movement is nothing new. But from an evolutionary perspective, change, rather than equilibrium achieved by supposedly rational and perfectly informed agents, is the focus. Capabilities learned and changed over time define strategies and influence the structure and performance of firms. Selection occurs, in an almost Darwinian way (Nelson 2015, 770), through the process by which resources, organizations, and firms adapt and survive in a changing environment (Malerba and Orsenigo 2015, 665). Path dependence and the accumulation of previous tacit knowledge are often behind apparent luck and success (Chandler 1990). Adaptation often involves learning processes for selecting the most adaptive ways of doing things. There are quality established academic journals that publish in English like Business History, Business History Review, Industrial and Corporate Change, Entreprises et Sociétés, Enterprise and History, Technological Forecasting and Social Change, Revista de Historia Industrial, Investigaciones de Historia Económica, and Revista de Historia Económica, which have been paying attention to the role of time and the influence of context on business for many decades. There is also a Journal of Evolutionary Economics published by Springer, but our Journal of Evolutionary Studies in Business is the first one that 
explicitly introduces the word 'Evolution' in combination with the word 'Business' in the very title of the journal. This combination has a significance that goes beyond terminology. It aims to contribute to a whole theoretical conception around the role of evolution in business organizations and the environment that surrounds them. Jim Quinn recently observed that evolution is not just change involving variation, selection, and survival, and suggested instead that we should consider the perspective of historians, who 'concern themselves with change in all its diversity' (Quinn 2015, 655). Evolutionary economic perspectives have contributed a lot to studying institutions and long-term changes in the organization of sectors and companies (Mowery and Nelson 1999; Nelson and Winter 1982; Quinn 2015; Murmann 2015; Nelson 2015). The implications of these studies for evolutionary perspectives in business are clear: firstly, the study of context is essential for understanding long-term entrepreneurship in sectors, regions, or types of companies like family businesses; secondly, the creation of capabilities to adapt to changes in markets, institutions, and technology determine the creation, survival, or the demise of organizations or the resources that made them competitive.

\section{Main research challenges}

There have been dramatic changes in the management field in the last thirty years. It is well known that the mass dissemination of new technologies, especially ICTs, has transformed organizations, the way they work, and their business strategies. The academic world has evolved in order to understand the changes that have taken place and to contribute with useful research results that address the future of organizations and that help us understand their competitive challenges. In the following paragraphs we will highlight the major changes that have occurred in the management field and their connection with academic research. 
The importance gained by horizontal 'processes' in business competitiveness is one of these changes. Terms like innovation management, knowledge management, quality management, and logistics have acquired key relevance due to the fact that they reflect processes that cut across organizations and require matrix structures. Indeed, such horizontal processes question the classical functional areas. Companies can only be competitive when mastering these horizontal processes and the compulsory relationship with networks that their implementation entails. Kotter (2014) describes this phenomenon as the need for dual organizational structures, and points to the importance of taking advantage of this approach.

The declining role of the classical functional areas is also clear in the production process where we have moved from pure 'production management' to 'management of the value creation chain'. Globalization and the ICT revolution have brought about significant changes that have required and still require a lot of research in order to gain an understanding of their scope and consequences. The concept of the value creation chain can be linked to three important issues. Firstly, the need for cutting-edge research activities in internationalization in order to better analyse and understand the relevant value chain models and business strategies. Secondly, in these global competitiveness scenarios, the role played by 'servitization' strategies within the value creation chain must be taken into account. Finally, new business models have been developed where new technologies and globalization highlight the key role of scalability.

The change from production chains to value creation chains is also associated with a third phenomenon: corporate social responsibility and management control indicators. In fact, management control has expanded its scope of activity to more sophisticated cost-tracking systems and the development of KPIs. This shift shows the growing importance of the 
connection between management control, strategy, balanced score-cards, and CSR. For us, the next step is now the change from pure CSR to the 'company with socially expanded aims'. As Segretin et al. (2014) have pointed out, the introduction of social aims into the statutes of companies seems a necessary step in a context where sustainability forms an irreversible part of the new business culture. Mintzberg (2015), in Rebalancing Society, goes in the same direction and emphasizes the changes that, from his point of view, large corporations need to adopt in relation to this issue.

In short, management has evolved from service and product development to a broader and more global vision of organizations involving innovation and creativity. In other words, cooperation becomes more important than hierarchies, and networks become more important than vertical organization charts. With regard to human resources, excellence is linked to managing people and talent.

Finally, in this new competitive scenario, reference must also be made to the so-called startup economy. Within the entrepreneurship field, the role played by start-ups, their links with entrepreneurial universities and innovative ecosystems, and the scale of the phenomenon are major changes and raise many research issues. Indeed, start-ups can even act as regional economic promoters, developing effective and strategic links with big corporations.

The obvious relationships between innovation and start-ups bring us to Entrepreneurship as a research field. This is a domain where research encompasses many different activities carried out by individuals and/or organizations resulting in new business in either new or already existing organizations. It is a field where intensive research has been carried out during the last decade and to which our journal also wishes to contribute. But, as Casson (2013) points out, there is no common theoretical framework or central research paradigm. It is in fact a 
research area with no clear boundaries because of the fact that entrepreneurial activities are viewed from multi-disciplinary perspectives and at various levels of analysis, using a variety of methods. Besides economics, there is a growing body of entrepreneurship research in politics, sociology, psychology, economic anthropology, business history, management, strategy, marketing and finance, and geography. This growing interdisciplinary character fits well with our journal's approach. Analyses of entrepreneurial activities can be developed at different levels: the individual or team level, the venture and firm level, and the macroeconomic level. The socioeconomic environment may influence entrepreneurial activities at all of these levels. Each of the components of this environment can play a significant role: institutions, regulations, and culture, as well as the availability of finance, knowledge creation processes, economic and social policies, or the presence of industry clusters.

With regard to the start-ups movement, in our journal we would like to prioritize the explorative side of entrepreneurship: the role and characteristics of individuals and teams (organizations). This is because the results of explorative entrepreneurship are mainly related to opportunity recognition, innovation, and venture creation, and the latter can take the form of the creation of new organizations or of new activities in existing organizations.

The combination of the social dimension of companies and the spread of the collaborative economy raise relevant questions concerning our current view of business and management activities. Profit models and market rationale are being questioned because of the fact that market and competition rules change with globalization. Global scalability in business networks creates multinational companies that are nearly intangible, where hierarchies and operational processes have nothing to do with the conventional approach of a manufacturing 
company rooted in the old industrial $20^{\text {th }}$-century model where 'big is beautiful' was the motto.

Within such a framework, the global vision of organizations in terms of innovation and creativity that we mentioned earlier leads to the issue of the organizational mindset. Some authors argue that a change is taking place from a 'dominant organizational mindset' where industry is the core (and where culture and the arts play a secondary role) to an 'emergent organizational mindset'. In this new mindset, the creative sectors (and their links with culture and the arts) are the core, and industry and services lose their leading role. The academic world has not been exempt from this trend and analyses of creative industries have progressed notably in recent years. For Cohendet and Simon (2015), companies must reinvent themselves and to do so they need a) to rethink structures in terms of open and transverse forms; b) to reformat processes by questioning projected values, risks, and ideas, and c) to reboot culture by assessing and cultivating cognitive work and the interplay of individual talents and communities. And all of this needs to take place in dialogue with the hierarchy and market values of the firm's current identity.

We strongly believe that the fields and subjects we have described here are relevant and that they raise more and more new challenges for academic research on management and many different obstacles for researchers to overcome. But subjects evolve rapidly and this calls for the development of research activities as fast as possible. The need for a quick response is crucial in order to avoid situations where publications appear when interest has been lost in the subject and it has been overtaken by new topics. Can we foresee how the world of business is going to change with the mass spread of the 'Internet of Things'? In a few years, 
financial organizations and banks, for example, will have little or nothing to do with their current form.

The set of factors and challenges related to management and business that we have summarized here are at the root of a new way of understanding competitiveness that calls for reinventing organizations and constantly rethinking reference frameworks. This must be one of the starting points for the research papers that our journal hopes to promote and publish.

\section{Our editorial team}

Due to the heterogeneity of organizations, of their capabilities, and of their learning processes over long periods of time, diversity in terms of structures, strategies, and pathways has been and is the standard in business. It is precisely for this reason that this publication contributes to the group of journals about business and change with an original asset, which is the large and diverse makeup of its editorial team. Our authors and readers have the opportunity to receive feedback and advice from associate editors located at eight institutions with headquarters in Europe, Asia, and America. Our strategy in this regard has been to select experts that can provide constructive and thought-provoking ideas for authors and readers in areas of expertise where most progress seems to be happening today in academia. For surveys on Management Challenges, the Associate Editor is Elena Golovko from Tilburg University in the Netherlands. On Creative Industries, we have Montserrat Pareja from the University of Barcelona. For submissions received on Entrepreneurship Esther Hormiga from the University of Barcelona and Sylvia Rohlfer from CUNEF, Madrid. Paloma Miravitlles from the University of Barcelona and Ying Ying Zhang from CUNEF will be associate editors for submissions on International Businesses. For Business History articles we have as associate editors Adoración Alvaro from CUNEF and Pierre-Yves Donzé from Osaka University in 
Japan. For the expanding and flourishing area of businesses in Latin America, the Associate Editors are Eloi Serrano from Tecnocampus/Pompeu Fabra University and the University of Barcelona and Araceli Almaraz from El Colegio de la Frontera Norte in Mexico. Finally, our journal wishes to publish articles about two non-traditional fields of interest in academic journals on business: Science and Business, and Online Resources for Researching Business. The Associate Editor for submissions dealing with Science and Business is Santiago López García from the University of Salamanca, and our Associate Editor for articles about online resources for business research and teaching will be Bernardo Batiz-Lazo from the Bangor University in the United Kingdom.

Paloma Fernández Pérez and Jaume Valls, whose expertise is in Business History and Entrepreneurship, are the first Editors-in-Chief of this journal, and welcome submissions from the diverse community of scholars interested in business from an evolutionary perspective, including organization studies, economics, business studies, history, sociology, politics, engineering, anthropology, and law. We particularly look forward to attracting contributions from recent Master's and $\mathrm{PhD}$ dissertations, in which excellent reviews of significant literature, debates, and questions can be regularly found, but which have no efficient platform for dissemination in academic journals. Expert knowledge from senior colleagues combined with current state-of-the-art work and debates about changes in business from new researchers can help our readers get involved in the essential mission of the scientist, which is, as Enlightenment thinking put it two hundred years ago, to help shed light in darkness and let readers think for themselves. The current search for useful synthesized knowledge to guide business practices and business research today can only benefit from quality overviews and new ideas. 


\section{References}

Casson, Bo; Pontus Braunerhjelm; Mauren McKelvey; Christer Olofsson; Lars Persson and Hakan Ylinenpää. 2013. "The evolving domain of entrepreneurship research.” Small Business Economics 41:913-930.

Chandler, Alfred D. 1990. Scale and Scope: The Dynamics of Modern Capitalism. Cambridge, MA: The Bellknap Press of Harvard University Press.

Cohendet, Patrick and Laurent Simon, L. 2015. "Introduction to the Special Issue on Creativity in Innovation.” Technology Innovation Management Review 5(7):5-13.

Kotter, John P. 2014. Accelerate (XLR8). United States of America: Harvard University Press.

Malerba, Franco and Luigi Orsenigo. 2015. "The evolution of the pharmaceutical industry." Business History 57(5):664-686.

Mintzberg, Henry. 2015. Rebalancing socxiety. Radical Renewal Beyond Left, Right, and Center. San Francisco: Berrett-Koehler Publ.

Mowery, David C. and Richard Nelson. 1999. The Sources of Industrial Leadership. New York: Cambridge University Press.

Murmann, Johann Peter. 2015. "Deepening the conversation between business history and evolutionary econòmics.” Business History 57(5):705-715.

Nelson, Richard. 2015. "Evolutionary economics and recounting of business history." Business History 57(5):769-772.

Nelson, Richard and Sidney Winter. 1982. An Evolutionary Theory of Economic Change. Cambridge, MA: The Belknapp Press of Harvard University Press.

Quinn, Jim. 2015. "Editorial: re-introducing evolutionary theory to business history: making sense of today's structures.” Business History 57(5):655-663. 


\section{Journal of Evolutionary Studies in Business}

Volume 1, Number 1, 1-14, January-June 2016

doi: 10.1344/jesb2016.1.j001

Segrestin, Blanche; Levillain, Kevin; Vernac, Stephane and Armand, Hatchuel. 2015. La "Société à

Objet Social Étendu”. Collection Economie et Gestion 15. Paris: Presses des Mines.

This is an Open Access article distributed under the terms of the Creative Commons Attribution-Non-Commercial-No Derivatives License (http://creativecommons.org/licenses/by-nc-nd/4.0/), which permits non-comercial re-use and distribution, provided the original work is properly cited, and is not altered or transformed in any way. 